\title{
Degradation of veterinary antibiotics and hormone during broiler manure composting
}

\begin{abstract}
The fate of nine veterinary antibiotics and one hormone in broiler manure during 40 days of composting was investigated. Results showed that composting can significantly reduce the concentration of veterinary antibiotics and hormone in broiler manure, making application of the post-compost manure safer for soil application. More than $99 \%$ of the nine antibiotics and one hormone involved in this study were removed from the manure during 40 days of composting. The target antibiotics and hormone showed short half-life in broiler manure composting, ranging from 1.3 to 3.8 days. The relationship between the physico-chemical properties of soil, manure and manure compost and its veterinary antibiotic and hormone concentration was statistically evaluated by Pearson correlation matrix. The concentration of veterinary antibiotics and hormone in manure compost was suggested to be affected by physico-chemical properties such as $\mathrm{pH}$, temperature, total organic carbon (TOC), total nitrogen (TN), total phosphorus (TP) and metal contents.
\end{abstract}

Keyword: Broiler manure; Veterinary antibiotics; Hormone; Composting; Degradation 